\title{
Finda a Língua, Fim da Linha
}

Resumo: A obra de Vladímir Maiakóvski, entremeada de grandezas e engrandecida ao longo das décadas por seu poder de comoção social, apresenta um ponto cego que, acreditamos, não pode ser deixado de lado - embora tenha sido em grande parte ignorado, em prol da imagem de força e bravura que interessaram, sobretudo, ao Regime. Assim, palavras como 'futuro' e 'quotidiano' - que, em sua obra, têm a força de conceitos - , quando levadas a sério, permitem que depreendamos a forte e ambígua relação do poeta com a necessidade de rompimento com a tradição, da qual, para ele, dependiam tanto a política quanto o amor, além da própria poesia. Trabalhar com essa dimensão de sua obra é procurar, atrás do mito criado por um governo, a dimensão de uma escrita que se ateve à tentativa de fugir da mera repetição do passado, encontrando nessa busca os seus limites.

PALAVRAS-CHAVE: Maiakóvski, quotidiano, futuro, comunismo, suicídio.

\section{A arte do novo}

ABSTRACT: The work of Vladimir Mayakovsky, interspersed with greatnesses and magnified over decades by its power to inspire o social upheavals, carries a blind spot which, we believe, cannot be left out - even though it was largely ignored in favor of an image of strength and bravery, that interested, above all, to the Regime. Expressions such as 'future' and 'everyday life', which in his work have the strength of concepts, when taken seriously, allow us to infert the poet's ambiguous relationship with the need of breaking with the tradition, on what depend, in his opinion, both politics and love, and even poetry itself. To work with these features of his work is to search, behind the myth created by a government, for features of a writing that attempted to escape from the mere repetition of the past, finding its limits in this quest.

KEYWORDS: Mayakovsky, everyday life, future, communism, suicide.

Disputem com avidez os pedaços de arte sadia, jovem e rude que lhes entregamos.

(Maiakóvski)

Q Â é segredo que a grande preocupação de Vladimir Maiakóvski [1893-1930] foi com relação ao futuro. Ao longo de sua vida, marcada pelo envolvimento político - em meio a todos os contrapontos com as questões do Regime ${ }^{2}$-, a premência da discussão a respeito de um passado que obstaculiza, tolhe e condena, bem como o reconhecimento da responsabilidade atribuída ao proletariado de acender essa problematização, sempre se mantiveram evidentes.

Nesse sentido, do seu lugar de participação nessa luta, o poeta promove uma aproximação entre o escritor e o operário. E é, inclusive, num poema endereçado ao próprio proletariado que ele afirma, em texto de 1918 (“Carta aberta aos operários' [Открытое письмо рабочим]), que “a revolução do conteúdo - socialismo-anarquismo - é inconcebível sem a revolução da forma: o futurismo" (MAIAKÓVSKI apudSCHNAIDERMAN, 1971, p. 120); ou seja, que não é possível uma Revolução que negligencie a necessidade de um comparecimento da arte aos tempos atuais -tratando-se, contudo, menos de uma revolução estética do que da simples atualização da arte, sem a qual, de acordo com o poeta, a poesia fatalmente deixa de cumprir o papel que lhe cabe.

O problema do escritor consiste em encontrar a mais viva expressão verbal a este ou aquele ciclo de ideias. O conteúdo é indiferente, mas, visto que toda época traz de maneira peculiar a necessidade de uma expressão nova,

000000000000000000000000000000000000000000000

${ }^{1}$ Tradutor e doutorando em Linguística pelo Instituto de Estudos da Linguagem (IEL/Unicamp). Em 2009 foi professor associado do Depto. de Língua Romena e Linguística Geral da Universitatea "Alexandru Ioan Cuza" (Iaşi, Romênia). e-mail: contra_sujeito@yahoo.com.br

${ }^{2}$ Sobre as questões relativas ao poeta e à política, sobretudo no que se refere à leitura que interessou ao Regime, cf., dentre outros, Roman Jakobson ([1931] 2006), Michael Holquist (1976) Robert Maguire (1987). 
também os exemplos que se denominam verbais devem ser contemporâneos. (MAIAKÓVSKI apud SCHNAIDERMAN, 1971, p. 142)

Sobre o advento significativo da contemporaneidade na literatura, Maiakóvski aponta, como divisor de águas, a obra de Antón P. Tchékhov [1860-1904]. Em um artigo sobre o autor, intitulado "Os dois Tchékhov" [Два Чехова, 1914], Maiakóvski afirma peremptoriamente que

durante quase cem anos, os escritores, amarrados entre si pelo mesmo tipo de vida, falavam com as mesmas palavras. A noção de beleza deteve-se em seu crescimento, rompeu com a vida e se declarou eterna e imortal. E eis a palavra como uma fotografia apagada de uma propriedade rural tranquila e rica. Ela conhece as regras da decência e do bom tom e flui sensata e harmoniosa, como uma berceuse. E além da cerca, enquanto isso, a vendinha cresceu e se transformou num bazar colorido e barulhento. $\mathrm{Na}$ vida tranquila das residências campestres irrompeu a multidão polifônica tchekhoviana dos advogados, fiscais de imposto, caixeiros e damas do cachorrinho. Os caixeiros viajantes são donos da vida. A velha beleza estalou como o colete de uma gordalhona mulher de padre. (...) Tchékhov foi o primeiro a compreender que o escritor apenas modela um vaso artístico, e que não importa se ele contém vinho ou porcarias. Ideias e argumentos não existem. Cada fato pode ser envolvido por uma admirável rede verbal. Depois de Tchékhov um escritor não pode dizer: não há temas. (MAIAKÓVSKI apud SCHNAIDERMAN, 1971, p. 144-145)

Vemos, então, que as considerações de Maiakóvski a respeito da nova arte se baseavam na busca por um tipo de experiência poética total com a atualidade do mundo: uma forma de pensar a arte como transversal às nossas experiências diárias, e, apesar disso, extrapolando o quotidiano - entendido como a aterrorizante repetição do passado, do qual seria preciso se fazer livre. E é nesse sentido que ele não se perguntou apenas 'arte para quê?'; afinal, no intento de filiar a poesia ao seu tempo - preocupado, então, também com a sua veiculação e o seu consumo - Maiakóvski desejou inclusive, marcado por expectativas ideológicas, bem situar o que responderia à seguinte questão: arte para quem?

Sua preocupação não era, com isso, nada abstrata - ou, se assim podemos chamar em Marina Tsvietáieva [1894-1941], meta-poética: “não para milhões, não para um só, não para mim. Escrevo para a própria poesia. A poesia, através de mim, escreve-se. Para chegar aos outros ou a si mesma?” (TSVIETÁIEVA, 1993a, p. 39). Para Maiakóvski, diferentemente, a arte deve ter uma finalidade expressa e concreta; e esta era a "lei da nova arte: nada de supérfluo, nada sem uma destinação" (MAIAKÓVSKI apud SCHNAIDERMAN, 1971, p. 133).

Para pensarmos o alcance dessa almejável experiência do artista com a sua obra e as suas circunstâncias, abdicando do velho e se lançando à novidade do seu século, lembremos que Wellek e Warren (1971), ao tratarem dos gêneros literários, encontram na obra de Víktor Chklóvski [1893-1984] uma contribuição importante, cremos, no que diz respeito ao estatuto do que aí se pode chamar de 'novo' em literatura:

Gostaríamos de sugerir alguns tópicos relevantes para a teoria dos gêneros, não obstante apenas tenhamos para oferecer perguntas e tentativas de resposta. Um dos tópicos diz respeito à relação dos gêneros primitivos (da literatura folclórica ou oral) com os de uma literatura evoluída. Chklóvski - um dos formalistas russos - sustenta que as formas de arte novas são "simplesmente a canonização de gêneros inferiores (subliterários)”. (Wellek e Warren, 1971, p. 294)

Ou seja, o que Maiakóvski faz é trazer o banal para dentro da poesia: aquilo que é tão próximo de nós, mas também, ao mesmo tempo, nos causa uma determinada estranheza - o novo que, de certo modo, já estava lá. 
Todos os escritores foram transformados em arautos da verdade, em cartazes da virtude e da justiça. E todos têm a impressão de que o escritor se afana com um único pensamento, com o qual ele quer corrigir e defender a você, e que vão apreciá-lo unicamente se ele, tendo explicado a vida, ensinar os demais a lutar contra ela. É dentre os escritores que se pescam os funcionários da instrução, os historiadores, os guardiões da moralidade. Selecionam-se ditados em Gógol, estudam-se os costumes da Rússia latifundiária em Tolstói, analisam-se os traços psicológicos de Lénski e de Oniéguin. Trocados em miúdo, os escritores são distribuídos pelas antologias e etimologias, e não os verdadeiros, os vivos, mas estes outros, inventados, privados de carne e sangue, serão enfeitados de louros. (MAIAKÓVSKI apud SCHNAIDERMAN, 1971, p. 140-141)

Ampliar a possibilidade de veiculação da poesia através da utilização de cartazes e panfletos ${ }^{3}$, por exemplo,

O trabalho do poeta da revolução não se esgota com o livro. $\mathrm{O}$ discurso em comício, a canção de front, o folheto de agitação, a leitura pelo rádio e a palavra de ordem que aparece nos flancos de um bonde são exemplos iguais e às vezes valiosíssimos de poesia (MAIAKÓVSKI apud SCHNAIDERMAN, 1971, p. 58)

bem como através da própria disponibilização do emprego poético a temas diversos e à parte daqueles consolidados pela tradição: eis o estranhamento que, invocado, participa da espoliação da figura imaculada do poeta e o conduz de volta ao mundo concreto, ao seu tempo, aos afazeres do dia a dia - "nosso trabalho é nossa pátria" (cf. MAIAKÓVSKI, 2001, p. 53).

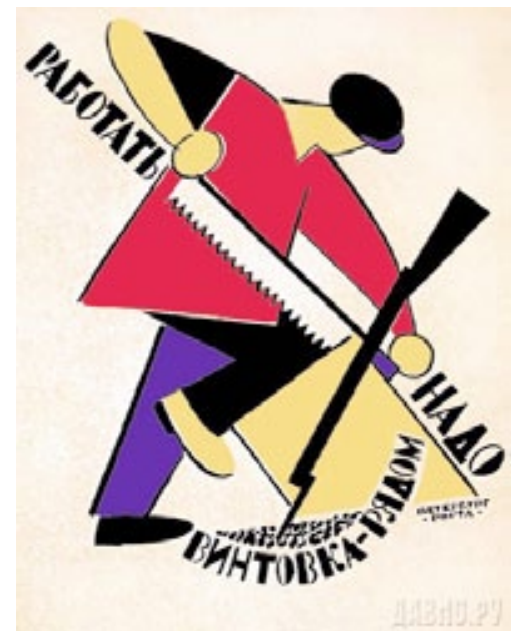

Работать надо - винтовка рядом ${ }^{4}$

Entretanto, nesse sentido, ao retomar o parecer de Chklóvski sobre as novidades, vemos que ele faz outra observação relevante a fim de contribuir para com a problematização das rupturas em cena na obra de Maiakóvski. Afinal, ele prossegue de modo a sustentar

que as formas de arte novas são "simplesmente a canonização de gêneros inferiores (subliterários). Os romances de Dostoiévski são uma série de romances criminais glorificados, romans à sensation, "os poemas de Puchkin provêm de versos de álbum, os de Blok de canções ciganas, os de Maiakóvski de poesia de jornal humorístico". (CHKLÓVSKI apud WELLEK; WARREN, 1971, p. 294)

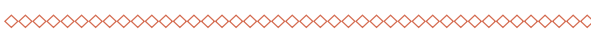

\footnotetext{
3 “A noção da amplitude do fenômeno poético, que não pode restringir-se aos textos declaradamente poéticos, está presente nele a cada passo" (SCHNAIDERMAN, 1971, p. 59).

4 “Trabalhar é preciso - [e] o rifle ao lado”. Cartaz da autoria de Maiakóvski para a Agência Telegráfica Russa - ROSTA [Российское телеграфное агентство - РОСТА], em que trabalhou de 1919 até 1922.]
} 
Assim, é como se esses autores se aproximassem entre si pelo coeficiente de "estranheza" que inscrevem, por suas obras, na cena literária que se apresentava antes deles. Com isso, podemos ponderar a real distância entre Maiakóvski e aqueles que criticava com avidez, e em que medida a novidade por ele pleiteada na literatura se distanciava de fato dos autores que ele critica. Tanto que, de fato, Maiakóvski vai criticá-los não exatamente por suas obras, e sim pelo que foi feito deles e delas em sua história de leitura - o que disso sedimentou e que havia se solidificado no gosto público da Rússia de então.

\title{
A arte, de novo
}

\author{
A palavra, a exemplo da estrutura social, \\ da vida quotidiana, da roupa, do ar, exige \\ "ventilação", "limpeza", "lavagem". (Maiakóvski) \\ Arakóvski afirmava que os poetas são "trabalhadores da palavra" e "organizadores da
linguagem", \\ A "criação artística" é reconhecida como trabalho necessário, de acordo \\ com as exigências do nosso consumidor autêntico de hoje, não como palavra \\ para o descanso, como "divertimento", mas como elaboração das palavras, ca- \\ pazes de organizar e melhorar a nossa atuação na vida. (MAIAKÓVSKI apud \\ SCHNAIDERMAN, 1971, p. 114)
}

já que a poesia seria, em última instância, uma forma de produção:

[ele] visava a perícia [...] do operário e do cientista, na busca das palavras exatas e novas que sacudissem a "poeira dos séculos" e devolvessem ao discurso sua intencionalidade e força de surpresa. Por isso mesmo, sabia chamar a atenção para todas as manifestações do espírito moderno e fazer apelo ao abandono de todas as velharias. (SCHNAIDERMAN, 1971, p. 54)

Dito isso, o poeta deverá ser entendido apenas como um produtor, um homem que se empenha na consumação de um produto como qualquer outro - produto este que não deverá lhe garantir o posicionamento em nenhum posto de destaque, vale lembrar.

E, nesse processo, é necessária uma desconstrução que abasteça o presente com uma sede de futuro; que revolva os ladrilhos de um passado paralisante, e deixe à mostra um terreno fértil para o novo - negação necessária, garantida por uma oposição que tira seu lucro do próprio fato de se opor, menos que do fato de existir efetivamente aquilo que, como tal, mereça ser renegado.

"Abaixo Puchkin!" é o grito de resposta do filho perante o grito do pai: "Abaixo Maiakóvski!" - do filho que vocifera não tanto contra Puchkin, como contra o próprio pai. O grito "Abaixo Puchkin!” é o primeiro cigarro fumado às escondidas do pai (que deixou de fumar), e fumado não tanto pelo próprio prazer como para desgostar o pai. (TSVIETÁIEVA, 1993b, p. 56)

Sobre sua saída da prisão, por exemplo (e se referindo às obras que leu no período em que esteve recluso) Maiakóvski (apud SCHNAIDERMAN, 1971, p. 91) afirma: "saí dali transtornado. O que eu li são os assim chamados grandes. Mas como é fácil escrever melhor do que eles!”. E Tsvietáieva encontra para isso um bom nome:

Autodefesa da arte. Para não morrer - em certas ocasiões - é necessário matar (e, antes de mais nada, dentro de cada um de nós). E assim Maiakóvski - contra 
Puchkin. No fundo, não é seu inimigo, mas seu aliado, o poeta mais contemporâneo do seu tempo, criador da sua época, exatamente como Maiakóvski da sua, e inimigo apenas porque o esvaziaram, transformando-o em ferro e deitando esse ferro sobre os ombros das gerações futuras (Poetas, poetas, mais do que a glória em vida temei os monumentos póstumos e as antologias!) Grito não contra Puchkin, mas contra o seu monumento. (TSVIETÁIEVA, 1932, p. 57)

Não é por menos que se chega a fazer, inclusive, uma aproximação entre os dois períodos em que viveram cada um dos poetas - e o cigarro do filho, ao que parece, talvez seja por vezes de fato capaz de renovar os votos da transgressão paterna de outrora, então embotada com o passar dos anos.

A era de Puchkin é tradicionalmente conhecida como A Era de Ouro da poesia russa, mas é crescente a convicção de que os anos que vão (aproximadamente) de 1890 a 1920 constituem minimamente uma segunda Era de Ouro e, possivelmente, um período até mesmo de maior significância que os anos vinte e trinta do século dezenove. (HOLQUIST, 1967, p. 126)

\section{Lugar incomum}

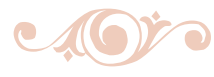

Hoje todos são futuristas. O povo é futurista.

(Maiakóvski)

UITo se fala sobre o movimento cubo-futurista ${ }^{5}$, e sobre a sua importância para a arte sovié-
tica do começo do século XX. Chegaremos, então, direto ao ponto em que, ao declarar que o futurismo obteve seu êxito, Maiakóvski revela já considerá-lo obsoleto, e chega a renegar alguns aspectos do movimento do qual ele mesmo havia sido um dos idealizadores:

Visto que o futurismo já morreu como ideia dos eleitos, ele não nos é mais necessário. Consideramos concluída a primeira parte do nosso programa: a destruição. O futurismo ocupou o seu lugar [...] na história da literatura, mas na União Soviética ele já acabou de desempenhar o seu papel. (MAIAKÓVSKI apud SCHNAIDERMAN, 1971, p. 26)

Entretanto, ele continuou a se proclamar futurista, até mesmo depois da Revolução de Outubro. O futurismo era para ele um slogan, pois em torno do termo se reuniam os que compartilhavam com ele uma atitude agressivamente inovadora no campo da arte.

A imagem do futurismo, porém, será confrontada por Maiakóvski a partir do posicionamento contemporâneo à Revista $L E F^{7}$ : o construtivismo. E o poeta chegaria a identificar, numa conferência

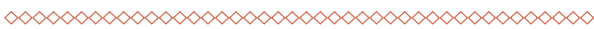

${ }^{5}$ Khliébnikov, Krutchônikh e Kamiénski também foram integrantes do futurismo russo - os dois primeiros, juntos de Maiakóvski e D. Burliuk, serão os signatários do manifesto 'Bofetada no Gosto Público'. Mas, sobre o nome 'futurismo', é preciso ressaltar que Fillipo Tommaso Marinetti, em 1914, ao visitar a Rússia, teve de reconhecer que as duas correntes diferiam: somente os nomes eram coincidentes, já que os propósitos e orientações ideológicas divergiam notavelmente (cf. GUERRA apud MAIAKÓVSKI, 1987). Sobre o movimento futurista no cenário russo, cf. também Leon Trotski (2007), Angelo M. Ripellino ([1971] 1986), Maria Kashéeva (1997), Edilene D. Matos (2005), entre outros.

6 “Ainda em 1923 ressaltava a importância de se conservar o uso do termo" (SCHNAIDERMAN, 1971, p. 26). Depreendese, então, que "o futurismo não foi para Maiakóvski qualquer coisa de superficial e adventício. Em seus lábios, soava como um apelo à derrubada das caducas fronteiras da arte burguesa - precisamente da arte decadente uma palavra de ordem que exortava a criar a cultura artística do futuro" (PAJITNOV; CHRÁGUIN apud SCHNAIDERMAN, 1971, p. 23)

${ }^{7}$ Revista da Левый фронт искусств [“Frente de Esquerda das Artes'], fundada em 1923 por Maiakóvski e por seus colegas futuristas. Seu propósito era o de aliar arte revolucionária e movimentação em prol da transformação social 
nos Estados Unidos, qual teria sido o erro crasso do movimento cubo-futurista: "na exaltação extremada pelo futurismo se revela o seu engano radical: a exaltação da técnica como tal, da técnica pela técnica" (MAIAKÓVSKI apud SCHNAIDERMAN, 1971, p. 26).

Todavia, Roman Jakobson [1896-1982] vai dizer que a obra de Maiakóvski apresenta uma preocupação capital que consiste no manejo poético com questões de natureza irracional por meio de uma abordagem objetivante - com o intento de mensurá-las, ponderá-las, significá-las racionalmente (cf. JAKOBSON, [1931] 2006). Não é por menos que, ao falar de si, o poeta assume se tratar de um artesão muito hábil nessa prática: "minha lógica é indiscutível. E minha matemática, infalível" (MAIAKÓVSKI apudSCHNAIDERMAN, p. 33). Prática esta que Maiakóvski havia paradoxalmente classificado, em sua homenagem poética a Serguéi Iessiênin [Сергею Есенину, 1926] - em razão de seu suicídio -, como o manuseio do impraticável:

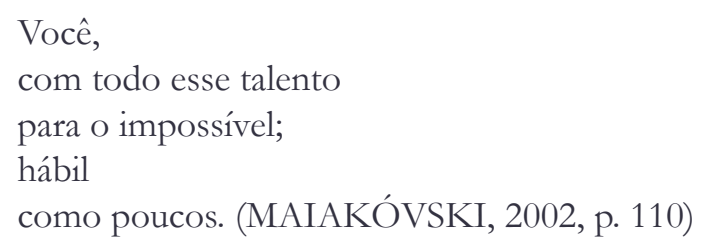

Esse elemento presente em seus textos, a racionalização do irracional, é de grande valor ao serem abordados os dramas vividos por ele no que se refere à poesia, ao amor e à política ideais. Ao se estranhar com o futurismo, Maiakóvski afirmaria, por exemplo, que o trabalho e os interesses da União Soviética não encontram mais seu reflexo nele - "o futurismo e a construção soviética não podem mais avançar lado a lado" (MAIAKÓVSKI apud SCHNAIDERMAN, p. 26) -, e sim na LEF, que, conforme ele mesmo afirma, não celebra a técnica apenas em sua pureza e caos, e sim a organização racional:

o construtivismo está intimamente ligado ao crescimento da cultura industrial e expressa o seu pathos intelectual, técnico e industrial. Ele formula a ideia da adequação racionalista, da exigência de economia, do cálculo matemático, do laconismo nos meios de expressão artística. Em sua tendência de aproximar a arte da indústria, o construtivismo renega o decorativo não motivado funcionalmente, ele esquematiza, logiciza e maquiniza a linguagem da arte. Em suas formulações mais extremadas, visa a liquidação da arte como esfera espiritual independente, a substituição do artista pelo engenheiro, pelo construtor, e a dissolução da obra artística na construção da vida, na criação de objetos adequados e racionais; por vezes, o construtivismo adere objetivamente às tendências tecnocráticas. (SVIERTCHKÓV apud SCHNAIDERMAN, p. 35)

Maiakóvski, que não negou seu forte apreço pela cientificidade ${ }^{8}$, encontra na proposta construtivista uma grande aliada:

$$
\begin{aligned}
& \text { Eu } \\
& \text { à poesia } \\
& \text { só permito uma forma: } \\
& \text { concisão, } \\
& \text { precisão das fórmulas }
\end{aligned}
$$

\footnotetext{
${ }^{8}$ Em lugar da contemplação tola da natureza, esta aparece a Maiakóvski como “objeto não aperfeiçoado” ('O inusitado’ [Необычайное], in 'Eu mesmo' apud SCHNAIDERMAN, 1971, p. 55). A ideia de que a ciência ainda iria livrar os homens da morte o fascinava. "Você não acha que é desse modo que adquiriremos a imortalidade? Pois eu estou inteiramente convencido de que algum dia não existirá mais a morte. Vão ressuscitar os mortos. Vou procurar um físico que me explique Einstein ponto por ponto. É impossível que eu não entenda" (MAIAKÓVSKI apud JAKOBSON, 2006, p. 29)
} 
matemáticas. (MAIAKÓVSKI, 2002, p. 110)

Entretanto,

em 8 de fevereiro de 1930, isto é, pouco antes do suicídio [...], Maiakóvski chegou afirmar, numa intervenção, que, do ponto de vista da aplicação didática, o construtivismo era a mais nociva de todas as tendências, e que ele repetia o erro do futurismo: a veneração pura e simples da técnica. (SCHNAIDERMAN, 1971, p. 36)

Mas, em todo caso, se Maiakóvski não deixou de se dizer futurista, tampouco deixou de defender o construtivismo - "embora não participasse do grupo e mesmo chegasse a travar polêmicas com o mais vigoroso deles: Iliá Selvinski” (SCHNAIDERMAN, 1971, p. 36) - o que, minimamente, reitera a complexidade de suas considerações sobre poesia, e evidencia suas audazes tentativas de realizar, de modo nem sempre unívoco, seus ideais político-artísticos.

\section{Sem mais...}

\section{- e nem menos \\ e nem menos}

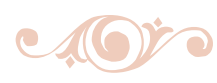

Na ponte dos anos escarnecido, redentor do amor terrestre, devo ficar e fico por todos, pagarei por todos

(Maiakóvski)

AIAkóvski se proclamava o cristo de uma nova proposta poética, um mártir que carregou
o estandarte no desbravamento dos caminhos para a arte do futuro: "sua teoria é quase sempre uma teoria do imediato, do contingente, a fundamentação de um trabalho, que se expõe para que os outros vejam como foi realizado e possam encontrar seu próprio caminho, à base desse ensinamento" (SCHNAIDERMAN, 1971, p. 30).

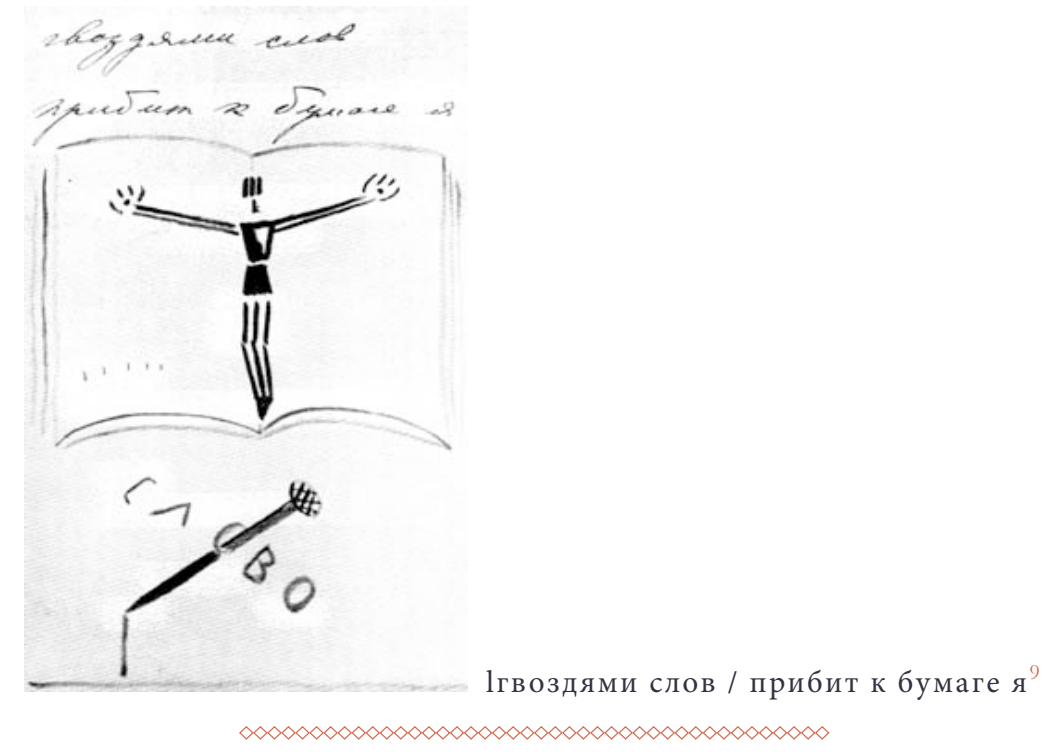

${ }^{9}$ Ilustração, feita pelo autor, de um excerto do poema ‘A Flauta-Vértebra’ [Флейта-позвоночник, 1915]. Este trecho, "estou preso ao papel com os pregos das palavras", aparece ao fim da obra (cf. MAIAKÓVSKI, 2002, p. 72). 
Escava, com sua bravata, o lugar legítimo do insustentável necessário ao seu intento - o que, ao invés de desmerecê-lo, deve mais fazer com que nos lembremos de uma célebre frase de J. Lacan, quando este diz só haver causa daquilo que falha ${ }^{10}$ : "eu arranquei da poesia as vestes da retórica; eu voltei ao essencial. Estudo cada palavra e o efeito que desejo produzir sobre o leitor: é o que fazem as pessoas que escrevem os anúncios de vocês. Eles não querem gastar em vão uma só palavra” (MAIAKÓVSKI apud SCHNAIDERMAN, 1971, p. 133).

Apesar, entretanto, de estar em meio a outros - sublinhemos o plural em "uma coisa está clara para nós: fomos nós que inauguramos a primeira página da novíssima história das artes" (MAIAKÓVSKI apud SCHNAIDERMAN, 1971, p. 120) -, entendemos que o poeta também prosseguiu muitas vezes solitário em sua jornada, o que é compreensível se temos em vista suas diferenças e entraves constantes com os movimentos e respectivos adeptos com os quais convivia ${ }^{11}$, bem como pela paraconsistência de suas convicções metamorfoseantes:

Sim, Maiakóvski é o mais viril e o mais corajoso de todos os que, pertencendo à última geração da velha literatura russa, e ainda por ela não-reconhecidos, procuraram criar laços com a Revolução. Sim, ele desenvolveu laços infinitamente mais complexos que todos os outros escritores. (TROTSKI, [1930] 2007, p. 205)

Na tragédia 'Vladímir Maiakóvski' [Владимир Маяковский, 1913] essa singularidade se desvela no palco:

No prólogo, Maiakóvski se apresenta ao público como "quiçá o último poeta" numa trágica cidade distorcida de modo expressionista. Ele proclama, calmo, zombeteiro e impávido, seu ódio pelos raios do dia [...] e promete "revelar nossas novas almas por meio de palavras simples como mugidos", para conduzir as pessoas até a felicidade de viver [...] e prover uma linguagem universal. Nesse breve monólogo, Maiakóvski pode tocar nalguns de seus próprios temas e traços, bem como nos do futurismo russo em geral (urbanismo, primitivismo, antiestetismo; os temas do desespero histérico, da incompreensão, e os da alma do novo homem e da alma das coisas). Durante a obra, fica a figura do poeta como profeta, ser superior, mas também condolente; mas toda a ação da tragédia se deve a pessoas fictícias e grotescas (um homem sem uma orelha, um homem sem cabeça etc.) ou a grupos com função de coro. Algumas das personagens menores apresentam solilóquios importantes. Essas personagens, todavia, exceto o “jovem convencional”, não passam de fragmentos do eu lírico do poeta, Vladímir Maiakóvski, mesmo quando, aparentemente, parecem separar-se dele, ou lhe serem antagonistas. (MARKOV, 1973, p. 140)

Ainda que seja possível dizer "sem exagero que havia em Maiakóvski reflexos de gênio. Ele não era [...] um talento harmonioso" (TROTSKI, [1930] 2007, p. 203) - algo que se estampa, por exemplo, na fala do 'ferreiro', personagem do Mistério-Bufo [Мистерия-Буфф, 1918] (MAIAKÓVSKI, 2001, p. 266-267):

Vamos!

Vamos pelas cidades e vilarejos andaremos, como bandeiras nossas almas penduraremos.

$\infty<\infty<\infty<\infty<\infty<\infty<\infty<\infty<\infty<\infty<\infty<\infty<\infty<\infty<\infty<\infty<\infty<\infty<\infty<\infty$

\footnotetext{
10 “... cada vez que falamos de causa, há sempre algo de anticonceitual, de indefinido. As fases da lua são a causa das marés quanto a isso, é claro, sabemos neste momento que a palavra 'causa' está bem empregada. Ou ainda, os miasmas são a causa da febre - isso, também, não quer dizer nada; há um buraco, e algo vem oscilar no intervalo. Em suma, só existe causa para o que manca" (LACAN [1964] 1998, p. 27)

${ }^{11}$ Cf., dentre outros: Viktor Shklovsky ([1941]1972), Zbigniew Folejewski (1963), Michael Holquist (1967), Boris Schnaiderman (1971)
} 
Saiam da sujeira

todos, a quem

enjoaram as tarimbas dos albergues noturnos.

O granito das cidades,

o verde das aldeias -

tudo é nosso.

O mundo é membro da comuna.

De fato, harmonia não se podia encontrar facilmente em diversos âmbitos de um período como aquele em que viveu o poeta, catastrófico, "no limite não-cicatrizado de duas épocas" (TROTSKI, [1930] 2007, p. 203). Esses fatos pelos quais passou a Rússia no início do século XX trouxeram consigo, aliás, implicações de tamanha extensão que podemos depreender relações importantes destes, inclusive, em autores como Friedrich Nietzsche - ao tratar do niilismo - com pontos relevantes em sua obra:

Os conflitos mundiais, o fracasso do socialismo e o crescente declínio das instituições coletivas e do Estado ratificam a desilusão do sujeito. Cada dia mais, o poder da técnica e suas crescentes conquistas foram tomando o lugar da participação individual junto a um sujeito descrente, desiludido e pessimista com seu futuro, um niilista passivo. Em outro extremo, radicais lideram revoluções e partem para o ataque através da força, capitaneando aquilo que podemos chamar de niilismo ativo ou completo. (JUNGES, 2005, s/p.)

E aí temos um ponto importante sobre o qual fazer considerações. Afinal, o poeta, que havia dito "sem ele [o comunismo] / não há amor para mim"12, vai se ver sem a própria possibilidade de amar, quando a utopia comunista, desmantelada, emudece junto à sua voz.

Para Maiakóvski, que levou às últimas consequências a fuga do lugar-comum como única saída para a redenção da palavra (e dos vínculos entre os cidadãos, os sujeitos e os enamorados), o amor terminou por não conseguir se manter firme; e isto, diferentemente do tédio, a vodka já não aplaca: os pregos que outrora fizeram do papel o varal soberbo de sua voz indômita, abandonaram a camisa amarela à lufada do assalto ${ }^{13}$.

Jakobson ([1931] 2006, pp. 37-38), em sua comovente elegia ao poeta, relembra trechos do bilhete derradeiro; nele a labareda se apaga, mas o resto da sua letra ainda teima como um borralho, para deixar bem claro que não há sequer para onde fugir: afinal, "a barca do amor quebrou-se no quotidiano"; e, sendo assim, "eu não tenho saída".

\section{exioro}

\footnotetext{
${ }^{12}$ Excerto do poema 'Para casa!'

${ }^{13}$ Remeto aqui aos poemas 'A Sierguéi Iessiênin' (1926) e 'A plenos pulmões' (1929-30), em que se encontram trechos célebres tais como "melhor morrer de vodka que de tédio!" e "morre, meu verso, como um soldado anônimo na lufada do assalto” (MAIAKÓVSKI, 2002, pp. 111 e 135). Sobre a blusa amarela de Maiakóvski, ver 'Blusa fátua' (cf. MAIAKÓVSKI, 2009, p. 238).
} 


\section{Referéncias OBibliagräficas}

FOLEJEWSKI, Z. Mayakovsky and futurism. Comparative literature studies, Penn State University Press (Pensilvânia), Special Advance Number, p. 71-77, 1963. Disponível em: <http://www.jstor. $\mathrm{org} / \mathrm{stable} / 40245613>$. Acesso em: 29/jul/2011.

HOLQUIST, M. The Mayakovsky problem. Yale French Studies, Yale University (New Haven), n. 39, pp. 126-136, 1967.JAKOBSON, R. (1931) A geração que esbanjou seus poetas. Trad. S. Gonçalves. São Paulo: CosacNaify, 2006.

JUNGES, M. Deus e a metafisica em Ockham e Nietżsche. Controvérsia, UNISINOS (São Leopoldo), v.1, n.1, jan-jun, 2005. Disponível em: <http://www.controversia.unisinos.br/index. php? $=1 \& s=9 \& a=37>$. Acesso em: 29/jul $/ 2011$.

KASHÉEVA, M. El futurismo. In: GONZÁLES, F. P. (org.). Historia de las literaturas eslavas. Madrid: Cátedra S.A., 1997.

LACAN, J. (1964) O seminário - livro 11: os quatro conceitos fundamentais. Trad. M. D. Magno. Rio de Janeiro: Jorge Zahar, 1998.

MAIAKÓVSKI, V. Antologia poética. $\sigma^{a}$ ed. Trad. E. Guerra. São Paulo: Max Limonad, 1987 . Mistério-bufo: um retrato heróico, épico e satírico de nossa época. $2^{a}$ ed. Trad. D. Beliaev. São Paulo: Musa Editora, 2001. 2002. . Poemas. $6^{a}$ ed.. Trad. A. de Campos; H. de Campos; B. Schnaiderman. São Paulo: Perspectiva,

. "Blusa fátua”. In: CAMPOS, H. et al. Poesia russa moderna. São Paulo: Perspectiva, 2009.

MAGUIRE, R. Red virgin soil. Londres: Cornell University Press, 1987.

MARKOV, V. Storia del futurismo russo. Torino: Einaudi, 1973.

MATOS, E. D. Um toque de balalaica para Maiakóvski, poeta da voz e do gesto. Revista Cultura Crítica, PUC-SP (São Paulo), n. 1, $1^{\circ}$ sem. 2005. Disponível em: <www.apropucsp.org.br/revista/rcc01_ r11.htm>. Acesso em: 29/jul/2011.

RIPELLINO, A. M. (1971) Maiakóvski e o teatro de vanguarda. São Paulo, Perspectiva, 1986.

SCHNAIDERMAN, B. A poética de Maiakovski. São Paulo: Perspectiva, 1971.

SHKLOVSKY, V. Mayakovsky and his circle. Trad. L. Feiler. Londres: Pluto Press, 1972.

TROTSKI, L. (1930) "O suicídio de Maiakóvski”". In: Literatura e Revolução. Trad. L. Moniz. Rio de Janeiro: Jorge Zahar, 2007.

TSVIETAIEVA, M. "Um poeta a respeito da crítica". In: O poeta e o tempo. Trad. F. Amaral. Lisboa: Hiena, 1993a.

TSVIETAIEVA, M. “O poeta e o tempo”. In: O poeta e o tempo. Lisboa: Hiena, 1993 b.

WELLEK, R.; WARREN, A. Teoria da literatura. $2^{\mathrm{a}}$ ed. Portugal: Europa-América, 1971. 